\title{
A inevitável travessia pelo tempo: de Grande sertão: veredas a A paixão segundo G.H.
}

\author{
Anderson Luiz Teixeira Pereira* \\ Universidade Federal do Pará \\ Belém, Brasil \\ Sílvio Augusto de Oliveira Holanda ${ }^{* *}$ \\ Universidade Federal do Pará \\ Belém, Brasil \\ Recebido em: 23/04/2019 \\ Aceito em: 14/o8/2019
}

Por isso, a quotidianeidade fala de si como o âmbito onde nos encontramos constantemente com a natureza. Os acontecimentos dão-se no tempo - isto não quer dizer que tenham tempo, mas que, aflorando e sendo-aí, vêm ao encontro como que atravessando um presente. Este tempo presente é explicitado como curso sequencial, que se desenrola continuamente através do agora; uma sequência de que se diz que tem uma direção única e irreversível.

(Martin Heidegger - O conceito de tempo, 2008)

Resumo: O presente trabalho propõe o exame do tempo em Grande sertão: veredas (1956), de João Guimarães Rosa, e em A paixão segundo G.H. (1964), de Clarice Lispector. Nesse sentido, o tempo, a priori, categoria estrutural de toda narrativa, é tomado como temática recorrente ao mundo ficcional, provocando a leitura crítica acerca da experiência temporal vivida e narrada pelos personagens Riobaldo e G.H., respectivos das obras supracitadas. Portanto, uma vez repassado à matéria da narrativa, o tempo reorganiza a realidade sui generis do mundo ficcional e nos impõe a necessidade do ato interpretativo.

Palavras-chaves: Tempo. Guimarães Rosa. Clarice Lispector.

Abstract: This paper proposes to examine the time in Grande sertão: veredas (1956), by João Guimarães Rosa, and A paixão segundo G.H. (1964), by Clarice Lispector. This way, time, structural category of the narrative, is taken as theme of the fictional world, fact that provokes the reading of the experience of time lived and narrated by the characters Riobaldo and GH, respective of the two novels abovementioned. Therefore, when it's taken as theme, the time reorganizes the reality of the narrative and, consequently, it establishes the necessity of interpretation.

Keywords: Time. Guimarães Rosa. Clarice Lispector.

Résumé: On propose l'examen du temps dans Grande sertão: veredas (1956), de João Guimarães Rosa, et dans A paixão segundo G. H. (1964), de Clarice Lispector. En ce sens, le temps, a priori, catégorie structurelle de tout récit, est considéré comme un thème récurrent du monde fictif, suscitant une lecture critique de l'expérience temporelle vécue et racontée par les personnages Riobaldo et G. H., respectifs des œuvres susmentionnées. Par conséquent, une fois passé dans le récit, le temps réorganise la réalité sui generis du monde fictif et nous impose la nécessité de l'acte interprétatif.

Mots-clés: Temps. Guimarães Rosa. Clarice Lispector. 


\section{Introdução}

É próprio da natureza da arte moderna, principalmente no que diz respeito à literatura, um movimento de escritura que busca problematizar tanto a constituição estrutural da narrativa quanto o jogo ficcional por ela forjado. Dessa concepção que, por exemplo, Rosenfeld (2006) caracteriza como "desrealização", sobressai o ponto crucial, o qual possibilita o enlace entre a literatura de Guimarães Rosa a de Clarice Lispector. Nesse sentido, o tempo é o elemento comum que permite o estabelecimento de uma leitura aproximativa acerca do universo rosiano e clariceano.

Em primeiro lugar, cabe ressaltar que tal processo, a nosso ver, é oriundo de uma experiência ficcional da modernidade literária, que fez dessa temática um problema recorrente à própria constituição da narrativa, como se observa, por exemplo, em Virgínia Woolf, James Joyce, Proust e em vários outros ficcionistas modernos.

Em segundo lugar, o estudo do tempo na literatura decorre de um horizonte temático oriundo da própria da obra. A interpretação dos elementos estéticos que se busca examinar só é possível em função de uma "resposta necessária à contingência do caráter simbólico da linguagem” (NUNES, 2009, p. 123). Isso justifica a possibilidade de interpretarmos a configuração temporal em romances modernos, pois o século XX está marcado pela reflexão sobre a temporalidade ${ }^{1}$, conforme atestaremos por meio de questões de ordem técnica, temática e discursiva nos romances de Guimarães Rosa e de Clarice Lispector que este trabalho aborda.

\section{A configuração temporal moderna e a consciência do tempo}

\footnotetext{
${ }^{1}$ Hans Meyerhoff (1976, p. 3) afirma que "seria inútil documentar essa dominante posição do tempo na literatura" em função de sua abrangência. Se seria inútil ou não, o fato a ser considerado é que a categoria do tempo, bem como a tematização deste, tornou-se um dos elementos da experiência ficcional na modernidade.
} 
O tempo constitui um aspecto fundamental da narrativa. Quer dizer, sua dinâmica possui um caráter duplo: toda experiência narrada se dá no tempo e, por outro lado, ele é um dos elementos necessários para a estruturação interna do discurso. É para essas duas questões que Paul Ricoeur, em seu extenso trabalho dedicado ao tempo na narrativa, dividido em três volumes, se volta.

Para tanto, esta discussão retomará especificamente o segundo volume ${ }^{2}$, cujo subtítulo é "a configuração do tempo na narrativa de ficção". Partimos das pressuposições de Ricoeur (2010) em virtude de uma palavra-chave para os desdobramentos ora pretendidos, que, trata-se do termo "configuração", o qual modifica o desenvolvimento do tempo no âmbito da narrativa ficcional. Isso quer dizer que, estando a literatura moderna liberta das amarras de um conceito unilateral de tempo, a experiência narrada torna-se objeto da própria experiência da narração.

Desse modo, segundo Ricoeur, o tempo na narrativa moderna está ligado ao problema geral da relação mimética. Em função de seu caráter inventivo, a configuração da narrativa ficcional projeta uma cisão entre o nível paradigmático da escala tripartida do tempo - passado, presente e futuro - inclusive em relação aos tempos verbais, e a temporalidade no nível interno do discurso narrativo (RICOEUR, 2010, v. 2, p. 17). É essa possibilidade de configuração que permite afirmar que a literatura moderna, uma vez suspensos os princípios temporais de ordem e de causalidade, se engendra a partir de diversos processos temporais dinâmicos e inovadores.

Outro ponto a ser considerado é a contingência do tempo para um caráter, senão filosófico, pelo menos pensante; no sentido de que o campo artístico provoca a esfera conceitual. As redes temporais tecidas no interior da estrutura narrativa, uma vez reconfiguradas, tornam-se objeto para interpretação.

Ao abordarmos a configuração temporal moderna, estamos diante de um elemento que nos impõe a tarefa da compreensão. Isto porque o estatuto temporal da ficção moderna tensiona o caráter mimético que medeia a relação

\footnotetext{
${ }^{2}$ A título de informação, o projeto crítico de Ricoeur (2010) trata, em três volumes, do tempo na narrativa histórica e ficcional. Para este trabalho, delimitamos nossa leitura apenas ao segundo volume, em virtude de que neste, o intelectual trata especificamente do problema do tempo na narrativa ficcional.
} 
entre ficção e realidade. Se afirmamos que o tempo é inerente à vida humana, ratificamos não apenas sua importância no âmbito da ficção, mas, principalmente, a necessidade de examinar o desempenho da atividade de reorganização e estruturação do mundo ficcional tanto em nível formal, quanto técnico e temático.

No que concerne ao campo artístico e, especialmente, ao seu desdobramento em relação ao enlace entre tempo e ficção, evocou-se, em função do caráter emergente da modernidade como novidade, a incorporação de novas formas, temáticas, conceitos, valores, etc., à literatura. Todos os novos procedimentos temporais adotados pelos grandes ficcionistas decorrem da experiência da modernidade. O tempo na literatura, nesse sentido, pode ser compreendido como a expressão da vida moderna, o que nos permite sustentar o pressuposto de que o estatuto temporal da literatura moderna não apenas recusa, mas também problematiza esquemas, estruturas e padrões clássicos da representação temporal.

Para abordarmos os procedimentos temporais modernos, é necessário refletirmos sobre um problema geral, de ordem formal, da narrativa, que tem relação com o que Ricoeur (2010) retomou sob o título de "enunciação e enunciado" e que, semelhantemente, Benedito Nunes (2008) também enfatizou em seu trabalho sobre o tempo:

É, sem dúvida, no plano da história que o tempo na obra literária é outro que não o real. Entretanto, o tempo da história, que denominamos imaginário, depende ainda do tempo real, que subsiste na conectividade do discurso em que aquele se funda, e à custa do qual aparece ou se descola, para utilizamos expressão anteriormente empregada, na medida de sua apresentação através da linguagem (NUNES, 2008, p. 27)

A referência acima diz respeito ao caráter duplo do tempo no discurso da narrativa que, apesar de ser um aspecto intrínseco à sua estrutura, possui uma peculiaridade para a literatura moderna, sobretudo, para o gênero romance, isto porque "A dimensão de configuração, em contrapartida, apresenta os traços temporais que resultam da transfiguração ou da metamorfose da sucessão em configuração." (RICOEUR, 2012, p. 305), o que justifica a pertinência da atenção 
ao problema da enunciação e do enunciado no estudo de Ricoeur sobre o tempo.

Ora, todos os procedimentos manifestados na possibilidade de manipulação dos acontecimentos a serem narrados se desdobram no ato da enunciação. É por isso que Ricoeur (2010, v.2, p. 103) afirma que "narrar já é 'refletir sobre' os acontecimentos narrados”. O filósofo francês ratifica o pressuposto de que é por meio do ato da enunciação que a configuração temporal constitui o privilegio da narrativa.

A grande questão levantada pelo autor de A metáfora viva (1975) é pensar até que ponto o tempo da ficção corresponde ao tempo da experiência fenomenológica. Ricoeur problematiza o sentido de narrativa moderna como mimesis e como ato de configuração. Não é por acaso, que para isso, ele se volte para a enunciação, pois, é, por meio dela que se pode constatar como o tempo da narrativa ficcional prefigura, ou não, a temporalidade externa à obra, mas não apenas isso, pois é no ato de configuração que se coloca à prova o princípio da inteligibilidade ${ }^{3}$ narrativa.

Que toda narrativa funda um estatuto temporal particular é um fato que não se pode contestar. Assim, a literatura moderna, que não busca apreender a realidade de maneira objetiva, adotou procedimentos técnicos que cumprem, entre outras finalidades, o papel de particularizar e problematizar a experiência temporal.

Chegamos ao âmago da nossa discussão: o romance moderno, em detrimento de sua raiz "comprometida originalmente com o tempo" (NUNES, 2008, p. 49), provoca a relação entre o tempo da experiência fenomenológica para adotarmos a terminologia ricoeuriana - e o tempo ficcional, possibilitandonos conceber o tempo como um elemento que provoca o pensamento, a linguagem e a realidade.

Adam Mendilow (1972) afirma que "O tempo afeta qualquer aspecto da ficção: o tema, a forma e o médium - a linguagem." (ADAM MENDILOW, 1972, p. 35). Ainda que ocasionalmente, tanto o tratado teórico de Ricoeur quanto o

\footnotetext{
${ }^{3}$ Para Ricoeur a questão fundamental da narrativa ficcional está na capacidade (poética) de estabelecer uma relação lógica para os acontecimentos, até então distintos, como um todo, possibilitando a compreensão da história.
} 
trabalho de Mendilow - que inclusive é citado por Ricoeur - tocam em pontos comuns relacionados ao tempo na ficção. Isso não decorre apenas em função de ambos os estudos assumirem como corpus de investigação gêneros literários modernos. Cremos que a convergência se dê em virtude de dois aspectos: primeiramente, em função da abertura da literatura moderna para uma concepção de tempo que excede o limite da mimesis aristotélica e, segundo, tal fato decorre do nexo entre três elementos: tempo ficcional, tempo vivido e enunciação.

Insistimos em ressaltar esses fatores por um motivo que, embora simples, é, consideravelmente, relevante, pois abordar a questão do tempo em Grande sertão: veredas e em A paixão segundo G.H. exigirá um exercício hermenêutico, no sentido de que nelas o tempo descerra o limite da representação e forja uma concepção de mundo sui generis. Desse modo, a experiência humana no tempo passa a ser objeto e condição da própria narrativa.

Nunes (1985), ao apontar, tanto a relevância do enlace tempo ficcional e tempo vivido quanto a importância do aspecto qualitativo do tempo em face do caráter quantitativo no laboratório da modernidade, vai ao encontro das ideias de Ricoeur e de Mendilow. O principal ponto comum entre eles é a ênfase no problema do deslocamento do ato interpretativo para o sentido não da cronologia das ações narradas, mas para o significado da percepção e da própria experiência humana no tempo. Essa questão se constitui como um elemento fundamental do nosso pretenso estudo do tempo e é retomada, sob diferentes perspectivas, pelos três intelectuais interrogados nesta seção.

Acrescentemos a isso, um elemento importantíssimo, o qual possibilita o elo entre a experiência fictícia do tempo e o mundo real. Configurar, no âmbito da narrativa, é uma operação que assume como medium a linguagem. Desse ponto de vista, a literatura moderna pode ser compreendida como um campo aberto para a construção de uma temporalidade original.

$\mathrm{Na}$ experiência ficcional da modernidade, a linguagem constitui o elemento fundador de um mundo literário que coloca à prova, simultaneamente, o limite do tempo da enunciação e do enunciado. O jogo temporal forjado pela obra desvela o próprio sentido do tempo, promovendo a possibilidade para a 
experimentação, ao passo que se confronta a própria realidade forjada no âmbito da ficção.

A linguagem é o intermédio justamente pelo fato de ela ser a possibilidade da configuração narrativa. Assim, "O tempo imaginário, condicionado pela linguagem, liga momentos que o tempo real separa, inverte a sua ordem, perturba a distinção entre eles, comprime-os, dilata-os, retarda-os e acelera-os” (NUNES, 1992, p. 350).

Narrar é uma tarefa que pressupõe o próprio tempo, mas que só é possível de ser realizada por conta da linguagem. Benedito Nunes (1985, p. 389) nos lembra ainda que "não se pode narrar o tempo, e só se pode narrar porque o tempo constitui a condição fundamental da experiência” (BENEDITO NUNES, 1985, p. 389. Poderíamos ir além, afirmando que só se pode narrar, também, porque é no âmbito da linguagem que se concretiza a narração. Se o enredo, $a$ priori, é composto por vários blocos dispersos, a linguagem, tomada pelo tempo, é o instrumento necessário para articular todo os acontecimentos.

Isso posto, temos de acrescentar à discussão em torno da configuração temporal do romance a questão da consciência do tempo que, considerando os postulados de Adam Mendilow, pode ser concebida como um problema central da arte de compor enredos:

Embora o romance mesmo, no sentido moderno da palavra, tenha
começado tão tarde, atingiu o seu impulso completo muito
rapidamente. Os criadores do que era, em potencial, uma nova arte,
provaram ser de todo conscientes dos problemas da ficção, e do mesmo
modo capazes de lidar com esses problemas. Muito cedo, o romance
adquiriu uma capacidade protéica de mudar sua forma e de adaptar
suas convenções para satisfazer suas necessidades variáveis.
(MENDILOW, 1972, p. 15)

Em vista disso, podemos considerar que o romance moderno é marcado por uma multiplicidade de tempos. Essa variedade nada mais é do que a manifestação da consciência do tempo, pois, conforme reitera Mendilow (1972), “Todo bom romance tem os seus próprios padrões e valores temporais e adquire sua originalidade pela adequação com que são veiculados ou expressos" (MENDILOW, 1972, p. 69).

Pouillon (1974), em seu trabalho sobre uma fenomenologia do tempo na 
literatura, também enfatiza que - assim como os outros estudiosos com os quais temos dialogado - o tempo consiste na condição preliminar da narrativa, que, por sua vez, visa a contar os acontecimentos humanos que decorrem na temporalidade e a ela subjazem. Além disso, o intelectual acrescenta outro fator que está ligado ao elo entre tempo e narrativa moderna: "é na psicologia do indivíduo que se faz mister buscar o sentido dos encadeamentos de acontecimentos que lhe são aparentemente infligidos, e não na pretensa estrutura prévia de um tempo destituído de surpresas." (POUILLON, 1974, p. 113). É valido ressaltar que, ao apontar esse fato, o escritor francês está retomando um conceito muito caro ao romance moderno, a durée, do filósofo Henri Bergson (1859-1941). Nesse sentido, abramos um parêntese para discorrer brevemente sobre o fulcro do pensamento bergsoniano.

Em Ensaio sobre os dados imediatos da consciência (1988), obra na qual se delineia grande parte do pensamento do filósofo francês no que concerne à sua concepção de tempo, a ideia de duração ${ }^{4}$, que é reiterada por meio da noção de unidade e de multiplicidade, é concebida como uma sucessão de momentos heterogêneos, os quais formam um todo indivisível. Bergson acrescentará ainda que "há uma duração real, cujos momentos heterogêneos se interpenetram, podendo cada momento aproximar-se de um estado do mundo exterior que é dele contemporâneo e separar outros momentos por efeito dessa aproximação" (BERGSON, 1988, p. 78).

Em outros termos, na seara literária, a aproximação a Bergson se manifesta por meio de uma busca por apreender o tempo vivido pelos personagens tal como ele se dá, ou seja, ao se descrever a experiência fictícia dos personagens, tenta-se

\footnotetext{
${ }^{4}$ Bergson (1988, p. 72) assinala que há duas concepções possíveis de duração, uma que seja pura e outra que se liga a ideia de espacialização do tempo. A primeira pode ser compreendida como a sucessão dos estados de consciência adquirida "quando o nosso eu se deixa viver". Seria, portanto, o fluir contínuo da sensação temporal, uma penetração mútua dos vários momentos de vida. A segunda, tem que ver com o estabelecimento de uma ordem de sucessão dos momentos, motivado por uma faculdade humana que permite ao indivíduo "não apenas perceber uma sucessão de termos, mas também de os alinhar em conjunto"; ou seja, os estados de consciência são concebidos como matérias que se alongam no espaço e preenchem uma linha contínua, como concebe, por exemplo a física e a matemática. Contudo, o tempo real para Bergson seria o tempo vivido, que não se limita a uma representação espacial, ou seja, não possui um caráter mensurável. O filósofo acrescenta ainda o fato de termos uma extrema dificuldade em representar a duração em seu caráter original. Ver GILLOUIN, (19--)
} 
transcrever a sensação de sucessão dos momentos qualitativo da "duração interior", no qual se apartam as convenções cronológicas em virtude de um fluxo ininterrupto, marcado por uma diversidade de acontecimentos.

Considerando a discussão acima, eis os motivos pelos quais podemos atestar a validade da reflexão de Pouillon sobre o tempo. A trama romanesca moderna, destituída do princípio mimético, projetou a possibilidade de uma concepção de tempo, cujo sentido só se completa por meio da existência dos personagens. Desse modo, ela relativiza o tempo da experiência e, do mesmo modo, particulariza a experiência do tempo. Outra razão está centrada no sujeito que narra, que ao invés de realizar uma narração artificial, que se pretenda objetiva, envolvido pelo tempo irrefreável, sofre da obsessão do tempo e se debate contra ele, a fim de apreender, por meio do próprio tempo, um significado particular dos acontecimentos narrados.

Exemplo desse processo são os romances de fluxo de consciência ou de corrente de pensamento. Enquanto que as epopeias e as tragédias clássicas, como as de Homero e as de Esquilo narravam as aventuras de personagens num espaçotempo externo, o centro mimético da ficção moderna encontra-se voltado para as questões relativas à subjetividade de um herói-humano, conforme podemos verificar mediante assertiva de Benedito Nunes (2008):

\footnotetext{
Seja que se o considere o pivô de uma revolução da forma romanesca ou o ponto de maturação artística do romance, o certo é que depois do realismo naturalista, inclusive psicológico, da segunda metade do século XIX, que procurou legitimar a ficção pela verossimilhança das situações, fundada no conhecimento de leis naturais, o centro mimético na consciência individual exigiu a compreensão introspectiva do personagem e a vivência dos acontecimentos exteriores. Isso aliviou e em alguns casos liberou o enredo da obediência ao princípio da causalidade estrita, indissociável do tempo físico. (NUNES, 2008, p. 56)
}

O tempo romanesco, sobretudo, naqueles surgidos no século XX, tornouse um aspecto relevante em todos os sentidos. Primeiramente, por exemplo, a distinção entre tempo do narrar e tempo narrado, basilar ao conhecimento sobre as estruturas da narrativa (GENETTE, 200o), nos romances de fluxo de consciência não podem ser concebidos, absolutamente, como uma relação mensurável, pois, na modernidade, não se narra propriamente os acontecimentos 
da vida, mas as suas importâncias.

Tempo narrado e tempo da narrativa é uma dúplice que, necessariamente, afeta a interpretação e o significado da obra. A respeito disso, Ricoeur (2010) afirma que "a comparação dos dois tempos se torna verdadeiramente o objeto de uma ciência da literatura quando ela se presta à medida." (RICOEUR, 2010, v.2, p. 132). O filósofo francês ratifica a questão levantada acima de que o tempo romanesco, mesmo em sua dimensão mais formal, abre-se para novos significados. Ricoeur (2010, v.2, p. 133) acrescenta, ainda, que comparar os dois tempos do discurso da narrativa - tempo narrado e tempo da narrativa - não se limita à "medida comparativa de duas cronologias", mas quer dizer que a interpretação de aspectos estruturais do tempo está “cada vez mais livre da linearidade, da consecução e da cronologia”. (RICOEUR, 2010, v. 2, p. 134).

Em segundo lugar, o tempo ficcional moderno se encontra, verdadeiramente, ligado à percepção particular do sujeito. Os artifícios utilizados para mensurar o tempo, como o relógio, o calendário, as estações do ano, o movimento dos corpos celestes, etc. ainda que possam ser relevados, principalmente, considerando os romances que problematizam o tempo, são colocados como elemento secundários da compreensão, conforme atestaremos por meio da análise de Grande sertão veredas e de A paixão segundo G.H..

\section{O assombramento do tempo: "viver é perigoso"; "viver não é vivível”}

O romance moderno, em sua raiz originária, surgiu voltado para o rompimento do sentido de arte como representação da realidade empírica. Importa ao artista tudo o que esteja para além de uma visão objetiva e objetificada do mundo. No que concerne ao aspecto da temporalidade, esse princípio se manifesta na obra, principalmente, por meio do ponto de vista da história, que já não sendo global, torna-se marcadamente limitado ao horizonte subjetivo dos personagens. Nota-se que Riobaldo e G.H., respectivamente, narradores de Grande sertão: veredas e de $A$ paixão segundo G.H., sendo eles 
mesmos os agentes da experiência narrada, o tempo se torna relativo e individual.

Na Literatura Moderna já não há mais relógios. É por isso que nos dois romances que ora analisamos o tempo pode ser compreendido como um contínuo, o qual, enfatizado os estados internos, passado, presente e futuro são atados, formando uma unidade constituída por momentos heterogêneos, conforme postulou Henri Bergson (1988) acerca da durée. Buscaremos demonstrar como essa característica, que a princípio possui um caráter abstrato e conceitual, é repassada à própria forma do romance.

Se examinarmos a estrutura de Grande sertão: veredas, um primeiro aspecto a ser notado da volumosa obra-prima de Guimarães Rosa é a ausência de divisão capitular. Esse fato, ao que parece, pode ser relacionado a dissolução do tempo cronológico, que uma vez esfacelado, garante ao texto a possibilidade de ser construído sob a égide de uma exaustiva empresa que busca pôr em relação a experiência temporal de Riobaldo: "Ai, arre, mas: que esta minha boca não tem ordem nenhuma. Estou contando fora, coisas divagadas." (ROSA, 1982, p. 19). Além disso, os pouquíssimos marcadores temporais que, a priori, permitiriam identificar precisamente os diversos momentos de história que compõem o universo ficcional, esboçam a ideia da vida humana como um fluxo, o qual é enfatizado pela tematização da travessia, que enquanto não encerrada, encontrase sempre em curso.

Assim, alguns dos episódios mais importantes da infância de Riobaldo são contados em função de uma necessidade que o personagem-narrador sente em acrescentar sentido a uma outra experiência de vida. Isto porque, como afirma Meyerhoff (1976, p. 49) "A coisa lembrada parece independente da data". Veja-se a história de Riobaldo com Diadorim. Logo nas primeiras páginas, o narrador menciona ao interlocutor o nome de Diadorim, mas só depois de muito já ter contado sobre sua vida no sertão, quando ele relata o seu primeiro encontro com o rapaz, ainda garoto, no porto do De Janeiro, é revelado o fato de que Diadorim e Reinaldo eram a mesma pessoa. Em termos cronológicos, Riobaldo conhece, primeiramente, seu amigo sob o nome de Reinaldo e só depois, quando já integrado ao bando de Joca Ramiro, é que o nome Diadorim é revelado, mas esta ordem não é considerada na narração. 
Essa configuração demostra que experiência ficcional em Grande sertão: veredas se traduz na medida em que se manipula a história narrada em virtude de um sentido subjetivo que ela manifesta. Eis aí um esforço enunciativo para transpor o tempo tal como ele é sentido pelo indivíduo para a própria estrutura do romance.

Em A paixão segundo G.H., em função da ausência de capítulos enumerados, sendo a obra constituída por trinta e três fragmentos, sua construção também antecipa a noção de um processo de vida inacabada, ou seja, de que o tempo, enquanto atributo relativo ao sujeito, permanece sempre no curso da própria existência. Nesse sentido, ainda que o romance clariceano se concentre num episódio derradeiro da vida da personagem G.H., motivado pelo confronto com a barata, diferentemente de Guimarães Rosa que focaliza uma linha de ação mais sólida - presa à aventura de uma vida inteira pelo sertão —, resguardadas as diferenças de enredo, em ambas as obras, o cerne da narração é uma semelhante experiência de vida que se desenrola no presente narrativo e a ele permanece presa. Nas duas obras se busca apreender, por meio de uma estrutura narrativa complexa, a dimensão amorfa, até caótica, no caso de Clarice Lispector, da temporalidade de seus personagens.

Duas características formais que apontam o fato de que tanto a obra rosiana quanto a clariciana podem ser interpretadas como escrituras atravessadas por uma temporalidade sui generis, assentes na ideia do fluir, são o "fluxo de consciência e o monólogo interior"5, sendo este último de caráter no mínimo problematizável.

O fluxo de consciência, abundantemente empregado em Grande sertão veredas e em A paixão segundo G.H., permite a construção da ideia de um tempo verticalizado, o qual tem que ver, certamente, com a "duração interior" bergsoniana. Esse tempo também apresenta um caráter opaco, pois nota-se que o fulcro da experiência de Riobaldo e de G.H. está centrado na possibilidade de expressar uma experiência pessoal difícil de ser materializada. Esse tempo como

\footnotetext{
${ }^{5}$ Como atesta Erich Auerbach (1976), no ensaio intitulado "A meia marrom", dedicado ao estudo da subjetividade na Literatura Moderna, principalmente, na obra de Virgínia Woolf, os meios utilizados para o desdobramento da interioridade das personagens são principalmente a corrente de pensamento e o monólogo interior. Ver AUERBACH, 1976, p. 482.
} 
contínuo, relativo à interioridade dos personagens, é misturado, fragmentado e, sobretudo, confuso. Como consequência desse processo, é instaurado na obra de Guimarães Rosa e de Clarice Lispector um movimento de escritura, como escreveu Benedito Nunes acerca de obra clariciana, que salta da "palavra ao silêncio e do silêncio à palavra" (NUNES, 1989, p. 135).

Analisando a temática da existência e da linguagem na obra de Clarice Lispector, o intelectual observa que "A acuidade reflexiva e a inquietação formam, nas personagens de Clarice Lispector, os elos inseparáveis da 'consciência de si'” (NUNES, 1989, p. 105). O fluxo de consciência, enquanto meio de expressão da interioridade, impõe à G.H a necessidade do dizer que, por sua vez, fracassa em detrimento da impotência da linguagem: "Falarei nessa linguagem sonâmbula que se eu estivesse acordada não seria linguagem" (LISPECTOR, 2009, p. 19). Para Riobaldo, cuja narração é proeminentemente reflexiva, a interrupção do silêncio é alcançada diante da tarefa de computar sua trajetória de vida, sem deixar de fora o seu futuro.

Há, em detrimento do fluxo de consciência, um movimento de alongamento do tempo, no sentido de que exposta a interioridade dos personagens, os processos internos assumem uma posição privilegiada no enredo dessas obras. O fluxo temporal apenas se dá mediante à corrente de pensamento. É por isso que o ato da narração, isto é, a quebra do silêncio, é tão necessária para os personagens-narradores. É por meio da palavra que, de alguma forma, se virtualiza a dinâmica da temporalidade, que no caso de G.H. assume um sentido muito mais ontológico em detrimento da perigosa travessia em busca de um novo modo de ser: "- Não. Eu não te contei tudo. Ainda queria ver se escapava contando a mim mesma só um pouco. Mas minha libertação só se fará se eu tiver o despudor de minha própria incompreensão." (LISPECTOR, 2009, p. 136).

Ainda a respeito da discussão acerca do fluxo de consciência como marca da complexidade do tempo na Literatura Moderna, Meyerhoff (1976) acrescenta que:

É o 'fluxo de consciência' que serve para esclarecer ou tornar inteligíveis o elemento de duração no tempo e o aspecto de um eu perdurável. A técnica é destinada a dar uma espécie de impressão visível e sensível de 
como é significativo e inteligível pensar sobre o eu como uma unidade contínua a despeito da multiplicidade mais surpreendente e caótica da experiência imediata. (MEYERHOFF, 1976, p. 34)

Com base nas considerações elaboradas pelo teórico supracitado, pode-se interpretar a recorrência do fluxo de consciência em Grande sertão: veredas e em A paixão segundo G.H. como recurso que, uma vez integrados à estrutura da obra, expressa o qualidade de um tempo irrefreável.

Por outro lado, a temporalidade das obras ora analisadas também está assente no desdobramento do monólogo como parte importante do epos narrativo. É importante ressaltar que a configuração do tempo nestas obras também engloba uma espécie de jogo fictício da estrutura do monólogo. Aliás, essa é uma questão fundamental a ser considerada em ambas as obras analisadas.

Apesar de o romance rosiano ser tomado por um extensivo monólogo, que, em nenhum momento sofre interferência direta de um agente externo, a narração de Riobaldo é polarizada por uma estrutura dialógica em virtude da presença física de um interlocutor ${ }^{6}$ - que surge como um estratagema para composição do relato: "Quero é armar o ponto dum fato, para depois lhe pedir um conselho. Por daí, então, careço de que o senhor escute bem essas passagens: da vida de Riobaldo, o jagunço” (ROSA, 1982, p. 166). No romance de Clarice Lispector, essa polarização é mais extremada, pois G.H., que se encontra sozinha em seu apartamento, diante da situação de incomunicabilidade, a fim de frear a “consciência solitária” e da necessidade de reconquistar, pela narração, o eu desagregado, é levada a inventar a presença de uma mão que ocupa o papel de um interlocutor imaginário ou de narratário. De todo modo, isto é apenas um parêntese necessário para problematizar o desenvolvimento do monólogo como estrutura fundante da experiência individual de Riobaldo e de G.H..

A respeito desta discussão, Danièle Sallenave (1976), em seu estudo acerca de teoria sobre o desenvolvimento do monólogo interior na literatura, aponta que

\footnotetext{
${ }^{6}$ A título de informação, no trabalho de Barbieri (2011), que examina as formas do tempo em Grande sertão: veredas, o autor defende a ideia de que a cena inicial da obra-prima de Guimarães Rosa é constituída pelo monólogo e pelo diálogo, que, na verdade, após interrogar alguns estudiosos que escreveram sobre o assunto, conclui que se trata de uma relativização do monólogo em decorrência da presença do interlocutor que, em nenhum momento, toma a palavra.
} 
este elemento não pode ser tomado apenas como um procedimento técnico englobado pelos escritores, porém, interessa investigar a sua finalidade e seus pressupostos no discurso literário. Se considerarmos isto, poderíamos afirmar que em Grande sertão: veredas e em A paixão segundo G.H., esse recurso é utilizado não apenas para manifestar os estados internos dos personagens e a expressão de seus pensamentos, mas principalmente para construir, já no nível da estrutura, a ideia de uma narrativa que se fragmenta por acompanhar o curso tresloucado da narração. Outro efeito que surge a partir do monólogo, em função de ele articular uma linguagem fluida para a narração, é o desenvolvimento do neologismo de Guimarães Rosa e da sintaxe inusitada de Clarice Lispector, uma vez que tais características, que são recorrentes a uma linguagem desmedida, ratificam uma espécie de quebra com o sentido lógico da palavra e, portanto, de uma visão objetiva do mundo.

O monólogo interior, enquanto tentativa de reproduzir a interioridade dos personagens, de "sintonizar a palavra com o pensamento fluente, espontâneo, reflexivamente encadeado" (NUNES, 2008, p. 64), enfatiza a absorção, por parte da ficção, da complexidade do tempo na modernidade. Nas duas obras que interrogamos neste trabalho, esse aspecto se torna muito mais significativo em função desse "eu" que narra, buscar não simplesmente o relato autobiográfico, mas, sobretudo, a compreensão da dimensão simbólica do tempo em relação à existência.

Após romper com o cotidiano arrumado e coisificado, tendo aderido ao "êxtase" que furta a estabilidade do "sistema" mundano (NUNES, 1989, p. 6o), G.H. experimenta vários momentos introspectivos, nos quais o tempo externo é completamente suspendido, dando o efeito de que um único minuto nesse estado de ruptura parece ter a duração de uma eternidade. É por meio dos sucessivos momentos de monólogo interior que se articula o pensamento e a linguagem como forma da própria narrativa, sendo este o modo pelo qual se expressa o sentido subjetivo da experiência da personagem, como se verifica em uma das falas em que G.H. relata a dificuldade em traduzir aquilo que sente: "Estou tentando te dizer de como cheguei ao neutro e ao inexpressivo de mim. Não sei se estou entendendo o que falo, estou sentindo" (LISPECTOR, 2009, p. 99). O 
monólogo interior recria uma estrutura temporal fragmentada. Esse jogo, que envolve tanto a forma do texto quanto o seu conteúdo, decorre, como estamos tentando mostrar, dessa busca em apreender a constituição da temporalidade tal como ela é sentida pelo personagem.

Em Grande sertão: veredas, os momentos introspectivos, apesar de serem alternados com a demanda da história, também recria o sentido de uma estrutura fragmentada, produzindo um efeito de apagamento da linha que separa o tempo externo (quantitativo) do tempo qualitativo. Para Riobaldo, o tempo é uma mistura entre o vivido e o pensamento reflexivo que surge a todo instante, como se observa a propósito na cena em que o ex-Jagunço narra o suposto pacto nas Veredas Mortas:

Sapateei, então me assustando de que nem gota de nada sucedia, e a hora em vão passava. Então, ele não queria existir? Existisse. Viesse! Chegasse, para o desenlace desse passo. Digo direi, de verdade: eu estava bêbado de meu. Ah, esta vida, às vezes não vezes, é terrível bonita, horrorosamente, esta vida é grande. Remordi o ar: - 'Lúcifer! Lúcifer' — aí eu bramei, desengulindo. (ROSA, 1982, p. 319)

O relato de Riobaldo-Tatarana transcrito acima demonstra o descompasso entre o tempo físico e o qualitativo. Outra cena da trama rosiana, entre várias que, também, reforçam essa característica da narrativa é o momento do cerco dos "Judas" - os jagunços que estavam sob o comando do traidor Hermógenes contra o bando de Riobaldo, enquanto eles estavam acampados na fazenda dos Tucanos. A certa altura, relatando o confronto que se sucedera, diz o narrador: "Vá de retro! - Nanje os dias e as noites não recordo. Digo seis e acho que minto; se der por cinco ou quatro, não minto mais? Só foi um tempo.” (ROSA, 1982, p. 26o). Quer dizer, a experiência temporal para o personagem se traduz, como ele mesmo diz, num "tempo no tempo". Eis aí um elemento que evidencia a sobreposição do tempo qualitativo sobre o físico. Importa menos a ocasião do acontecimento e sua duração concreta do que os sentimentos e as angústias experimentados no ocorrido. Outra parte interessante deste mesmo episódio, é quando os inimigos matam os cavalos que estavam desprotegidos do lado de fora da casa da fazenda. A situação de penúria dos pobres animais, que é descrita de maneira plástica, captura a dimensão do sofrimento, do medo e da raiva sentida 
por todo o bando de Riobaldo, que nada podiam fazer. Registra-se, na construção desta cena, a sensação de um tempo paralisado, que expressa a tessitura de uma temporalidade humana que o tempo físico não comporta.

Tendo sido apontado o fluxo de consciência e o monólogo interior como dois atributos relevantes no romance de Guimarães Rosa e de Clarice Lispector, tomados como formas oriundas da temporalidade da obra, pondo em elisão a estrutura tradicional da narrativa, é importante evidenciar, considerando a obra literária como unidade de sentido, que os personagens Riobaldo e G.H. vivem o que denominamos de assombramento do tempo, ideia reiterada, tanto em Grande sertão: veredas quanto em $A$ paixão segundo G.H., por meio do mote temático de que a vida impõe um peso à existência, conforme se verifica no texto transcrito abaixo:

De primeiro, eu fazia e mexia, e pensar não pensava. Não possuía os prazos. Vivi puxando difícil de difícil, peixe vivo no moquém! quem mói no asp'ro, não fantasêia. Mas, agora, feita a folga que me vem, e sem pequenos dessossegos, estou de range rede. E me inventei neste gosto, de especular ideia. O diabo existe e não existe? Dou o dito. Abrenúncio. Essas melancolias. O senhor vê! existe cachoeira; e pois? Mas cachoeira é barranco de chão, e água se caindo por ele, retombando; o senhor consome essa água, ou desfaz o barranco, sobra cachoeira alguma? Viver é negócio muito perigoso... (ROSA, 1982, p. 11 - grifos nossos)

Vou criar o que me aconteceu. Só porque viver não é relatável. Viver não é vivível. Terei que criar sobre a vida. E sem mentir. Criar sim, mentir não. Criar não é imaginação, e correr o grande risco de se ter a realidade. Entender é uma criação, meu único modo. (LISPECTOR, 2009, p. 19 - grifos nossos)

Durante sua suposta conversa com o seu interlocutor, Riobaldo, em seu discurso, expõe uma importante lição sobre o tempo: se existe uma relação entre o tempo vivido e a narração, esta é perpassada por uma tensão, pois, estabelecido um confronto entre esses dois polos, cujo resultado é a expurgação da matéria pretérita em direção ao presente narrativo, promove-se a abertura para se refletir sobre a experiência vivida, conforme já havíamos mencionado na seção terceira quando comentamos o episódio da segunda travessia pela Liso do Sussuarão.

Desse modo, analisando os excertos transcritos acima, com base em uma perspectiva comparativa, podemos compreender que embora os personagensnarradores de Guimarães Rosa e de Clarice Lispector estejam cerrados em 
mundos completamente distintos, o primeiro no sertão e o segundo no espaço urbano, as experiências, os dilemas morais e éticos e as circunstâncias de vida possuem um caráter universal. É nesse sentido que afirmamos que Riobaldo e G.H. vivem o assombramento do tempo, porque embora eles sejam partes do mundo ficcional, eles experimentam as contradições, a ambivalência e a dualidade do homem moderno em toda sua complexidade. Ambos os personagens sentem o peso da vida acumulada. E afirmamos mais. É para se livrar desse fardo que eles narram. Tomar a palavra é em último caso a busca desenfreada para dar sustentação a esse fluxo temporal permanente que é a vida humana.

A experiência de G.H., como bem observou Benedito Nunes (1989), é paradoxal. E esse aspecto está presente na dimensão do próprio texto em virtude de o discurso da personagem ser constituído com base em ideias e imagens contrárias, como fica evidenciado no seguinte trecho: "Toda compreensão súbita é finalmente a revelação de uma aguda incompreensão. Todo momento de achar é um perder-se a si próprio" (LISPECTOR, 2009, p. 14).

Lembremo-nos de que a personagem de A paixão segundo G.H., antes do evento que perturba a sua existência "arrumada", encontrava-se absorvida pela banalidade do cotidiano. Aliás, essa é uma característica geral das personagens de Clarice Lispector, as quais refugiadas à sombra estável de suas rotinas, num dia qualquer, são provocadas por um acontecimento inesperado que surge como veículo da "ruptura com o mundo"7, como se verifica, por exemplo, na história de Ana, no conto "Amor". Assim, G.H., que até certo ponto possui um "viver domesticado" - como ela mesma diz —, diante do silêncio, da solidão e apartada do convívio social, presa na superestrutura do edifício onde mora, percebe, principalmente quando seu olhar atravessa e é atravessado por um rosto inexpressivo registrado numa fotografia, que sua identidade pessoal é uma máscara: "Naquela manhã, antes de entrar no quarto, o que era eu? Era o que os outros sempre me haviam visto ser, e assim eu me conhecia. Não sei dizer o que

\footnotetext{
7 Utilizamos o termo que Benedito Nunes (1989) emprega para descrever o momento de tensão conflitiva dos contos e dos romances de Clarice Lispector, diferentemente de outros estudiosos que atribuíram a esse mesmo aspecto da literatura clariciana o termo "epifania'.
} 
eu era." (LISPECTOR, 2009, p. 22-23).

G.H. se dá conta do quanto sua vida até então fora falseada em função da "pressa de viver tudo o que tivesse que viver" (LISPECTOR, 2009, p. 24), tendo como ponto culminante a compreensão de que ela havia humanizado demais a vida. Mas esse saber é paradoxal, pois só é alcançado por meio da desagregação do eu, que se dá no "confronto com a barata, ponto de ruptura do sistema em que a personagem vive" (NUNES, 1989, p. 73).

A imagem metafórica da perda da terceira perna, que é o elemento que permite à personagem a concretização da travessia da desaprendizagem humana, reafirma, uma vez mais, o assombramento do tempo, no sentido de que, recompondo-se o sujeito por meio da palavra narrada, o novo modo de ser da personagem se torna um contínuo, isto é, uma existência marcada por uma temporalidade durativa, ideia esta que é ratificada pelos verbos empregados na forma do gerúndio logo no início do romance.

O personagem de Rosa não experimenta esse processo brusco de ruptura com o mundo, de desaprendizagem humana e de despojamento do eu como se dá no âmbito ficcional do romance de Clarice Lispector, entretanto, algo peculiar no que concerne à temporalidade dos dois universos literários com os quais estamos lidando tem que ver, certamente, com o fato de que a espinha dorsal da obra rosiana $^{8}$ e clariciana está assente, em grande parte, na elaboração do paradoxo, tanto como recurso estilístico quanto sentido para qual caminha a narrativa. Júlio de Paula (2010), acerca da relação entre tempo e paradoxo em Grande sertão: veredas, destaca que há a presença de "um princípio de ordenação do tempo e, por extensão, da narrativa, assinalado desde o início por um paradoxo: é preciso sair do fluxo temporal para que se possa dispor o tempo em uma estrutura narrativa apreensível por nosso entendimento" (PAULA, 2010, p. 70).

Ora, se admitirmos tal assertiva elaborada pelo estudioso, a qual está pressuposta na fenomenologia ricoeuriana, concluiremos que a presença desse

\footnotetext{
8 Outro estudioso que também assinala a presença do paradoxo na obra-prima de Rosa é Ettore Finazzi-Agrò (2006, p.13): "a escrita rosiana parece balançar constantemente entre a pontualidade e inconclusão, entre a opacidade e a transparência, entre uma linguagem pedregosa e uma expressão aérea (entre romance e poesia, enfim), levando quase fatalmente à impossibilidade de fechar o texto e o seu discurso na inelutabilidade dos seus limites físicos."
} 
paradoxo apenas reitera o fracasso da narrativa diante da impossibilidade de sair do fluxo temporal, que no nível da estrutura se confirma por meio da fragmentação e da "duração interior". Afirmamos isso porque se o que Riobaldo e G.H. buscam é organizar a experiência temporalmente esparsa para elucidar a si mesmos, e eles reconhecem esse fito, de todo modo, os dois acabam falhando, pois, sendo eles narradores de suas próprias histórias, instaura-se uma relação de tensão entre o existir e o narrar. Portanto, o paradoxo surge como resultado da incapacidade da linguagem ordinária de reconfigurar o tempo subjetivo. Prova disso é o teor especulativo-filosófico que interfere a todo instante no relato: "Viver é perigoso" e "Viver não é vivível”, repetido em vários momentos das obras.

A relação de Riobaldo e Diadorim exemplifica a questão mencionada acima de que o paradoxo, que a princípio está circunscrito no plano do discurso (a ambiguidade da relação), também se dá na configuração temporal da obra. $\mathrm{O}$ narrador não poderia antecipar ao interlocutor o fato de que seu mui amigo era na verdade uma mulher. Se assim o fizesse, a dualidade que advém da presença de Diadorim e que anima o enredo de Grande sertão: veredas se perderia, de acordo como atesta Walnice Galvão (1972: "E sua destreza maior, que é negacear a respeito do sexo de Diadorim, nomeando-o sempre como homem ao mesmo tempo que semeia incontáveis pistas de sua feminidade" (WALNICE GALVÃO, 1972, p. 87). Júlio de Paula (2010), ainda a respeito de Diadorim, acrescenta o fato de que a ambivalência desse personagem marca, na verdade, "a presença simultânea de dois elementos ou conjuntos de elementos que, posto contraditórios (ou justamente por isso), reúnem-se para exprimir algo que escapa à linguagem corriqueira, automatizada”. (PAULA, 2010, p. 84).

Por fim, todas as questões levantadas neste artigo demonstram a complexidade e o trabalho exaustivo com a linguagem e com a temporalidade realizado por Guimarães Rosa e por Clarice Lispector. A questão do tempo que se integra à concepção de mundo das duas obras estudadas aqui abre caminho para desdobrarmos o enraizamento da reflexão na própria linguagem literária. A construção de Riobaldo e de G.H. como personagens humanos, que problematizam o significado de humanidade e, por consequência a existência, permite a primazia da elaboração de um estudo do tempo, no sentido de que este 
surge como uma questão que inquieta o homem. Esse movimento da escritura, que funde reflexão e linguagem, é o fulcro do assombramento temporal vivido pelos narradores que engendram a experiência ficcional.

Num cômputo geral, com base na especulação comparativa entre a experiência de Riobaldo a de G.H., verifica-se que o jogo temporal forjado, já no âmbito da ficção, encena uma concepção de tempo que advém da experiência da modernidade. Embora a narração desses personagens esteja marcada pela reminiscência, isto é, a dimensão da existência pretérita que o presente narrativo busca interrogar, ela não se desprende do fluir temporal que reaparece por meio do mote da travessia temporalmente incompleta e inacabada, que recaí ainda sobre a elucubração do futuro vindouro.

O circuito de vida de Riobaldo e de G.H. são muito próximos. Trata-se de uma existência tênue, apaziguada pelo quotidiano aparentemente estável, que esconde as incertezas do indivíduo quanto ao significado da existência no tempo. O Riobaldo que narra é um homem velho, que viveu muitos fatos em sua trajetória e presenciou as transformações físicas históricas, sociais e culturais do sertão. G.H., de quem não podemos precisar a idade, de todo modo, é uma mulher madura, com uma carreira profissional, aliás artística, consolidada, com uma vida social e financeira aparentemente estável.

Contudo, esses dois personagens até antes do início da narração, encontram-se presos a um sistema que lhes furta a possibilidade de pensar sobre as suas vidas. Ao tomarem posse da linguagem, que fervilha a existência arrumada, assumem o risco do perder-se, que é ao mesmo tempo um achar-se. Ao final da narrativa, quando voltam ao estado de silêncio, quando a linguagem cala, já não são mais os mesmos. Todo o processo de vida que experimentaram e continuarão a experimentar ultimar-se-á numa nova compreensão de si que caminha sempre na direção da mudança.

Como concluiu Benedito Nunes acerca da temporalidade em Grande sertão: veredas, mas que, também, é cabível à $A$ paixão segundo G.H.:

Na abordagem filosófica de uma obra literária, como a que aqui tentamos fazer, é a filosofia que aprende com a literatura. Aprende que a experiência do Tempo - do tempo humano, do tempo não físico, - 
requer, para configurar-se, uma trama particular, uma forma de história ou de intriga; aprende, para expressá-lo com palavras de Paul Ricœur, que 'o tempo se torna tempo humano na medida em que é articulado sob o modo narrativo e que a narrativa atinge a sua significação plena quando se torna condição da existência temporal' (NUNES, 1985, p. 402)

Essa tensão entre o existir e o narrar, sutilmente presente no trecho supracitado, expõe como a ficção lida com o problema do tempo, sendo esta, portanto, uma maneira de conhecimento, que escapa, por exemplo, do olhar científico.

\section{Considerações finais}

A travessia hermenêutica em busca do desdobramento do tempo em obras de ficção moderna, conforme buscamos realizar neste trabalho, demonstra que a literatura se apresenta sempre aberta a novos caminhos interpretativos. Grande sertão: veredas e A paixão segundo G.H., respectivamente de João Guimarães Rosa e de Clarice Lispector, mesmo depois de várias décadas de acolhimento crítico, podem ser lidas como objetos estéticos, cujo caráter inconcluso possibilita o desenvolvimento de uma experiência estética que se atualiza em cada nova proposta de leitura.

Na abordagem de Grande sertão: veredas e A paixão segundo G.H, é impossível lançar-se ao desafio da interpretação, sem que se ponha em jogo a estética literária e o horizonte de expectativas da própria obra. Sendo o tempo um dado da existência humana e, também, um elemento intrínseco à narrativa, seu entendimento deve ser tomado com base na experiência narrada pelos personagens, pois a linguagem é o suporte que fundamenta as relações humanas com o mundo e, por assim dizer, com o tempo. Desse modo, propondo-se a investigação destas duas obras, surge como questão substancial o enlace entre tempo e a ficção, uma vez que este é instaurado já no plano da própria obra literária. 
Em Grande sertão: veredas e em A paixão segundo G.H., por mais que se tematize a temporalidade, a seara artística não tem compromisso com o conhecimento teórico e conceitual. Pelo contrário, o tema do tempo aparece em decorrência da centralidade desse problema diante do existir. Como já buscamos evidenciar, o narrador de Guimarães Rosa e o de Clarice Lispector não possui o intuito de definir o que é o tempo, mas estando em relação com o mundo, defrontam-se contra ele.

\section{Referências}

AUERBACH, Erich. A meia marrom. In: Mimesis. Trad. Suzi Frankl Sperber. São Paulo: Pespectiva, 1976. p. 471-502.

BARBIERI, Márcio José Pivotto. O tempo das formas em Grande Sertão: Veredas. São Paulo, 2011. 125 p. Dissertação de Mestrado em Literatura Brasileira, Universidade de São Paulo.

BERGSON, Henri. Ensaio sobre os dados imediatos da consciência. Trad. João da Silva Gama. Lisboa: Edições 70, 1988.

FINAZZI-AGRÒ, Ettore. A perfeita imperfeição: transição e permanência em Grande sertão: veredas. Suplemento Literário de Minas Gerais, Belo Horizonte, maio de 2006.

GALVÃO, Walnice Nogueira. As formas do falso: um estudo sobre a ambiguidade no Grande sertão: veredas. São Paulo: Perspectiva, 1972.

GENETTE, Gérard. Discurso da narrativa. Trad. Fernando Martins. Lisboa: Vega, 2000.

GILlOUIN, René. Berson. Trad. José Pérez. São Paulo: Cultura Moderna, [19--]. HEIDEGGER, Martin. O conceito de tempo. Trad. Irene Borges-Duarte. Lisboa: Fim do século, 2008.

LISPECTOR, Clarice. A paixão segundo G.H. Ed. crítica organizada por Benedito Nunes. Brasília: CNPq, 1988. A paixão segundo G.H. Rio de Janeiro: Rocco, 2009. 
MENDILOW, Adam. O tempo e o romance. Trad. Flávio Wolf. Porto Alegre: Globo, 1972. 270 p.

MEYERHOFF, Hans. O tempo na literatura. Trad. Myriam Campello. São Paulo: McGraw-Hill, 1976.

NUNES, Benedito. O tempo na narrativa. São Paulo: Ática, 2008. . A clave do poético. São Paulo: Companhia das Letras, 2009. Experiências do tempo. In: NOVAES, Adauto (Org.). Tempo e história. São Paulo: Companhia das Letras; Secretária Municipal de Culturaz ,1992. p. 131134 .

Grande sertão: veredas: uma abordagem filosófica. Bulletin des études portugaises et brésilennes. Paris, ADPF, n. 44-45, p. 389-404, 1985.

. O drama da Linguagem: uma leitura de Clarice Lispector. São Paulo: Ática, 1989.

. Tempo. In: JOBIM, José Luis (Org.) Palavras da Crítica. Rio de Janeiro: Imago, 1992. p. 343-366.

PAULA, Júlio Cesar Machado de. O que ajunta espalha: tempo e paradoxo em Grande sertão: veredas, de Guimarães Rosa, e Nós, os do Makulusu, de Luandino Vieira. Minas Gerais, 2010, 154 p. Tese de Doutorado em Literatura Comparada, Universidade Federal de Minas gerais.

POUILLON, Jean. O tempo no romance. Trad. Heloysa de Lima Dantas. São Paulo: Cultrix; São Paulo: EDUSP, 1974.

RICOEUR, Paul. Tempo e narrativa. Trad. Márcia Martinez de Aguiar. São Paulo: Martins Fontes, 2010. v.2.

Entre tempo e narrativa: concordância/discordância. Trad. João Batista Botton. Kriterion, Belo Horizonte, n. 125, p. 299-310, jun./2012.

ROSA, João Guimarães. Grande sertão: veredas. Rio de Janeiro: José Olympio, 1956.

Grande sertão: veredas. Rio de Janeiro: José Olympio, 1982.

ROSENFIELD, Anatol. Reflexão sobre o romance moderno. In: Texto e Contexto I. São Paulo: Perspectiva, 2006, p. 75-97.

SALLENAVE, Danièle. Sobre o monólogo interior: leitura de uma teoria. In: HAMON, Philippe et alii. Categorias da narrativa. Trad. Fernando Martins. 
PEREIRA, Anderson Luiz Teixeira; Holanda, Sílvio Augusto de Oliveira

Lisboa: Arcádia, 1976, p. 113-137.

* Mestre em Letras/Estudos Literários pelo Programa de Pós-Graduação em Letras da Universidade Federal do Pará.

** Professor associado IV da Universidade Federal do Pará. Possui pós-doutorado em Estudos Românicos pela Universidade de Lisboa. 